GS21

\title{
Geological Risk Analysis for Horizontal Wells based on Drilling Campaign in the Cretaceous Burgan Formation, Kuwait
}

\author{
Omran Al Zankawi* (Kuwait Oil Company), J. Bardalaye (Kuwait Oil \\ Company), H. Al-Enezi (Kuwait Oil Company), K.H. Al-Azmi (Kuwait Oil \\ Company), F. Al-Matrood (Kuwait Oil Company), R. Kotecha (Kuwait Oil \\ Company), J. Ahsan (Kuwait Oil Company), A. Safar (Kuwait Oil Company) \\ $\&$ J.H. Al-Humoud (Kuwait Oil Company)
}

\section{SUMMARY}

The Cretaceous Burgan Formation of the Greater Burgan Field, Kuwait (Fig. 1) is the largest clastic reservoir in the world. To increase production from these clastic reservoirs, a number of horizontal wells have been drilled during the last four years.

The targeted reservoir sands show a lot of heterogeneity. Predicting sand continuity in such a scenario is a challenge. Moreover, velocity anomalies in the shallow sections and structural complexity in some areas brings in a great deal of uncertainty in the depth prediction. Due to these reasons, landing the well in the desired reservoir section and drilling the drain hole with maximum pay zone exposure becomes very difficult. To mitigate these risks, a methodology has been developed to analyze the geological risks involved before drilling a horizontal well. 


\section{Introduction}

The Cretaceous Burgan Formation of the Greater Burgan Field, Kuwait (Fig. 1) is the largest clastic reservoir in the world. To increase production from these clastic reservoirs, a number of horizontal wells have been drilled during the last four years.

The targeted reservoir sands show a lot of heterogeneity. Predicting sand continuity in such a scenario is a challenge. Moreover, velocity anomalies in the shallow sections and structural complexity in some areas brings in a great deal of uncertainty in the depth prediction. Due to these reasons, landing the well in the desired reservoir section and drilling the drain hole with maximum pay zone exposure becomes very difficult. To mitigate these risks, a methodology has been developed to analyze the geological risks involved before drilling a horizontal well.

\section{Methodology}

The geological risks were categorized in terms of expected remaining oil column (ROC) at the toe and heel, quality of sand expected, lateral continuity of sand bodies, and throw of faults expected along the well path versus expected sand thickness. The estimate of the ROC gives an idea about how long the well will produce dry. The sand quality and lateral continuity helps to estimate the final expected net-to-gross. The expected sand thickness versus throw of fault measure gives an idea if we have to exit the reservoir while negotiating the fault. The successes of all these wells were measured in a scale of Length of Lateral Vs Net Sand Thickness.

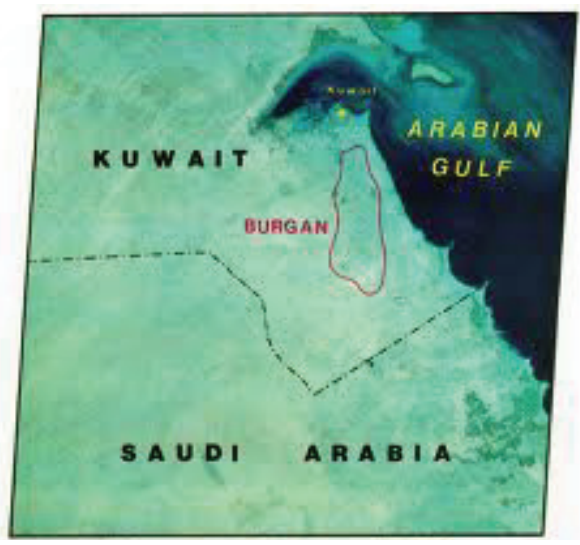

Figure 1 Location map of the Greater Burgan Field, Kuwait

\section{Conclusions}

Defining the ROC at the toe and heel has helped in fixing up safe production allowables for the wells. The depositional dip of the Burgan sands being NE-SW, wells drilled along this direction exhibit better sand continuity. Also predicting small magnitude faults near to the landing point and along the drain-hole has helped in better landing and drain-hole placement. Thus, applying the risk assessment methods described above, we have been successful in placing the laterals in an average of $80-90 \%$ of quality reservoir.

\section{References}

Al-Eidan, A. J., W. B. Wethington, and R. B. Davies [2001] Upper Burgan reservoir distribution, northern Kuwait: Impact on reservoir development. GeoArabia, 6(2), 179-208.

Bou-Rabee, F. [1996] Geologic and tectonic history of Kuwait as inferred from seismic data. Journal of Petroleum Science and Engineering, 16, 151-167.

Brennan, P. [1990b] Greater Burgan field, Kuwait, Arabian basin, in E. A. Beaumont and N. H. Foster, eds., AAPG Treatise of Petroleum Geology, Atlas of Oil and Gas Fields: Structural Traps, 1, 103-128.

Strohmenger, C. J., P. E. Patterson, G. Al-Sahlan, J. C. Mitchell, H. R. Feldman, T. M. Demko, R. W. Wellner, P. J. Lehmann, G. G. McCrimmon, R. W. Broomhall, and N. Al-Ajmi, [2006] Sequence stratigraphy and reservoir architecture of the Burgan and Mauddud formations (Lower Cretaceous), Kuwait, in P. M. Harris and L. J. Weber, eds., Giant hydrocarbon reservoirs of the world: From rocks to reservoir characterization and modeling. AAPG Memoir 88/SEPM Special Publication, 213-245. 